\title{
BMJ Global Health Under-five malnutrition among Palestine refugee children living in camps in Jordan: a mixed-methods study
}

\author{
Nada AbuKishk (D) , ${ }^{1}$ Hannah Gilbert, ${ }^{2}$ Akihiro Seita, ${ }^{1}$ Joia Mukherjee, ${ }^{2}$ \\ Peter J Rohloff ${ }^{3,4}$
}

To cite: AbuKishk $\mathrm{N}$, Gilbert $\mathrm{H}$, Seita A, et al. Under-five malnutrition among Palestine refugee children living in camps in Jordan: a mixed-methods study. BMJ Global Health 2021;6:e005577. doi:10.1136/ bmjgh-2021-005577

Handling editor Seye Abimbola

- Additional supplemental material is published online only. To view, please visit the journal online (http://dx.doi.org/10. 1136/bmjgh-2021-005577).

Received 3 March 2021 Accepted 23 May 2021

\section{Check for updates}

(c) Author(s) (or their employer(s)) 2021. Re-use permitted under CC BY-NC. No commercial re-use. See rights and permissions. Published by BMJ.

${ }^{1}$ Health Department, UNRWA Jordan, Amman, Jordan ${ }^{2}$ Department of Global Health and Social Medicine, Harvard Medical School, Boston, Massachusetts, USA

${ }^{3}$ Division of Global Health Equity, Brigham and Women's Hospital, Boston, Massachusetts, USA

${ }^{4}$ Center for Research in Indigenous Health, Maya Health Alliance Wuqu' Kawoq, Tecpan, Guatemala

Correspondence to Dr Nada AbuKishk; n.abu-kishk@unrwa.org

\section{ABSTRACT}

Background Jordan hosts the largest Palestine refugee population in the world. The United Nations Relief and Works Agency for Palestine Refugees in the Near East (UNRWA) is the primary healthcare provider for Palestine refugees. To better inform UNRWA's health programme, we conducted this study to assess the prevalence and determinants of malnutrition among Palestine refugee children in Jordan and to analyse caregiver perceptions of food insecurity and structural barriers to accessing food. Methods A cross-sectional study was conducted with a randomly selected sample of 405 households, for children under 5 years old in two refugee camps in Jordan, Jerash and Souf. Sociodemographic, food insecurity, diet quality and child anthropometric data were collected. Also, twenty in-depth interviews were conducted with children's caregivers, along with two focus group discussions with UNRWA staff.

Results Out of the 367 participants, the prevalence of stunting was $23.8 \%$ in Jerash and $20.4 \%$ in Souf $(p=0.46)$, and overweight was $18.2 \%$ versus $7.1 \%$, respectively $(p=0.008)$. However, high food insecurity in Jerash was $45.7 \%$ and $26.5 \%$ in Souf ( $p=0.001$ ), with no significant difference after multivariable adjustment. Qualitative perspectives saw food insecurity and low-quality children's diets as largely mediated by job and income insecurity, especially marked in Jerash due to the lack of Jordanian citizenship.

Conclusion We found a moderate-to-high prevalence of stunting and overweight levels among Palestine refugee children, which are three times higher than the 2012 Demographic and Health Survey data for Jordanian nonrefugee children. High rates of household food insecurity were closely tied to households' lack of essential civil and economic rights. We call for international collective efforts to expand economic livelihoods for Palestine refugees and to support UNRWA's ongoing operations.

\section{INTRODUCTION}

According to the United Nations High Commissioner for Refugees, a refugee is a "person forced to flee their country because

\section{Key questions}

What is already known?

- There is limited information available on the nutritional status of Palestine refugee children in Jordan.

What are the new findings?

- It provides up-to-date estimates of child stunting and overweight in two Palestine refugee camps in Jordan, with high food insecurity related to income.

What do the new findings imply?

- Overcrowding and eating calorie-dense, nutrientpoor food contribute to child obesity.

- It also discussed the ways in which refugees suffer from food insecurity and thier coping mechanisms.

of violence or persecution'. ${ }^{1}$ Palestine refugees are the oldest and largest refugee population in the world. According to the United Nations Relief and Works Agency for Palestine Refugees in the Near East (UNRWA), 700000 Palestinians became refugees following the Arab-Israeli war of 1948, settling as a stateless population in sixty-one permanent refugee camps across Lebanon, Syria, Jordan and the Occupied Palestine Territory of Gaza and the West Bank. ${ }^{2}{ }^{3}$ UNRWA has been providing primary healthcare, education, relief and social services for 5.7 million registered refugees since $1950 .^{2}$

Ensuring children's optimal growth and development is a fundamental human right and an essential priority. ${ }^{4}$ This is especially important for refugee children who are disproportionately affected by undernutrition and overnutrition ${ }^{5}$ and are less likely to have access to appropriate healthcare, nutrition and social services. ${ }^{6}$ Roughly $40 \%$ of the Palestine refugee population are children ${ }^{7}$; thus, understanding their nutritional status is important for setting programme priorities. The Palestine refugee population in Jordan is the largest in the world, with approximately 
370000 Palestine refugees living in ten camps. ${ }^{8}$ In 2019 , $29 \%$ of all children less than 5 years of age served by UNRWA health centres lived in Jordan. ${ }^{9}$ The most recent Jordan Demographic and Health Survey (DHS) from 2012 included only 245 children from refugee camps, with a prevalence of stunting of $9.6 \%$ versus $7.6 \%$ in the general non-refugee Jordanian population and a prevalence of overweight of $0.9 \%$ versus $1.8 \%$ in the general population. ${ }^{10}$ A repeated DHS in 2017 did not adequately sample refugee children; therefore, updated estimates could not be provided. ${ }^{11}$

Within Jordan, UNRWA's maternal and child health work has focused primarily on care delivery at health centres. ${ }^{12} 13$ There is limited ongoing monitoring of the health status of children who do not attend UNRWA centres for vaccination or acute illness. In order to assist UNRWA with priority setting for child nutrition interventions in Jordan, we conducted a mixed-methods study to determine the prevalence, determinants and perceptions of food insecurity and nutrition in children living in two camps.

\section{METHODS}

\section{Study design and setting}

There are ten recognised and three unofficial Palestine refugee camps in Jordan, which hosts nearly 370000 inhabitants. In addition, 2.2 million Palestine refugees live outside these camps. ${ }^{8}$ Camp inhabitants have significantly lower socioeconomic status and heavier reliance on UNRWA and other aid relief services than refugees who have successfully moved into community-based settings outside camps. ${ }^{14}$ We conducted a cross-sectional household-based study using sequential explanatory mixed methods, ${ }^{15}$ in two Palestine refugees' camps, Jerash and Souf, from October to December of 2019. Both Jerash and Souf have a population density of roughly 38000 residents $/ \mathrm{km}^{2},{ }^{8}$ compared with a population density of 3000/ $\mathrm{km}^{2}$ in Jordan's capital Amman. ${ }^{16}$ These two camps were chosen as they represent the two socioeconomic extremes among the camps within Jordan. Jerash has the highest rate of poverty $(52.7 \%)$ and the lowest rate of Jordanian citizenship (6\%) of any camp. Souf, on the other hand, has a much lower poverty rate of $24.4 \%$, and nearly all residents (98\%) have obtained Jordanian citizenship. $^{814}$

Institutional Review Board (IRB) approval was obtained from the Harvard Medical School IRB (HMS-IRB190581) and the UNRWA Research Review Board. The project was supported by the director of health department at UNRWA Headquarters as well as the chiefs of health programmes and relief and social services at the UNRWA Jordan Field Office.

\section{Study participants}

The study included Palestine refugee households with children under the age of 5 years old living inside the two camps. Households were excluded if the child had a physical disability or medical condition prohibiting accurate anthropometric measurements. In addition, focus group discussions (FGDs) were conducted with UNRWA staff, including health workers, social workers, women's programme staff and administrative staff. To ensure in-depth perspectives on nutrition dynamics within the camps, only staff with a minimum of 2 years of work experience at UNRWA were invited to participate in FGDs

\section{Quantitative sampling and data collection}

We calculated the sample size required to estimate the proportion of children with stunting with a precision of $5 \%$ and baseline prevalence stunting estimates taken from 2018 UNRWA health centre data (23\% for Jerash and $7 \%$ for Souf), ${ }^{9}$ allowing for a $10 \%$ refusal rate. The planned sample size was 407 children (297 children for Jerash and 110 for Souf).

We then used a simple random sampling technique to select households for participation. We used Q-Geographic Information System ${ }^{17}$ software to create two camp maps from satellite imagery and to select a simple random sample. Data collectors then used GPS coordinates to locate selected homes. The Research Electronic Data Capture software ${ }^{18}$ was used for data collection. Data collectors were trained on study methodology and child anthropometry by the lead author, a professional nutritionist, using UNICEF materials. ${ }^{19}$ Written consent was obtained from at least one biological caregiver or legal guardian. In homes with more than one child under 5 years of age, one child was randomly chosen for data collection, by numbering all the children in a list and then choosing a random number from the list to pick a child.

\section{Quantitative measures}

A structured questionnaire queried household demographics, socioeconomic status and food insecurity, in addition to child-specific demographic, anthropometric and previous-day diet recall. We used the WHO Child Growth Standards and definitions for anthropometric indicators including underweight (weight-for-age z-score $<-2$ SD), stunting (height/length-for-age $z$-score $<-2$ SD) and overweight (body mass index-for-age z-score $>=+2 \mathrm{SD}) .{ }^{20}$ We also assessed the double burden of malnutrition, which is defined as the proportion of children who are simultaneously stunted and overweight. ${ }^{21}$

For food insecurity assessments, we used the Food and Agriculture Organization's Food Insecurity Experience Scale, an eight-item scale covering the prior month. ${ }^{22}$ Question responses include rarely (once or twice in the past 4 weeks) one point, sometimes (three to ten times) two points and most of the time (more than ten times) three points. ${ }^{23}$ We dichotomised the food insecurity score, considering participants who responded 'most of the time' at least once as highly food insecure.

For child dietary intake, we used the WHO previous-day diet recall template to derive two WHO Infant and Young Child Feeding Practices indicators: minimum 
dietary diversity (proportion of children who received foods from four or more food groups within 24 hours) and minimum consumption of iron-rich foods (proportion of children who receive at least one iron-rich food within 24 hours).$^{24}$

\section{Quantitative data analysis}

We used Stata/IC V.15.1 ${ }^{25}$ for statistical analyses and the WHO's AnthroPlus (Geneva, Switzerland) to calculate anthropometric indicators. ${ }^{26}$ We conducted bivariate and multivariable logistic regression to explore the association between stunting, overweight and high food insecurity status and covariates. We assessed the fit of multivariable models using serial nested likelihood ratio tests and the Hosmer-Lemeshow goodness of fit test.

\section{Qualitative sampling and data collection}

We conducted 20 semistructured interviews with primary caregivers from a subset of participating households (12 in Jerash and eight in Souf) to elicit information about experiences of food security and caregiver perceptions of children's diets. Participants were chosen purposively ${ }^{27}$ to include variation in household poverty and food insecurity. The lead author conducted interviews using an interview guide, which is given in the online supplemental file. Interviews lasted an average of $45 \mathrm{~min}$ and were audio-recorded with permission. All interviews were conducted in Arabic in a private home room, with only the primary caregiver present.

In addition, two FGDs were carried out with local UNRWA staff-one in Jerash and one in Souf with 10 participants in each FGD. Participants all had a minimum of 2 years of experience working with UNRWA, and most participants were themselves Palestine refugees and camp residents. The FGD followed an interview guide given in the online supplemental file. The lead author conducted the FGDs in Arabic and inside UNRWA health facilities. FGDs lasted around $60 \mathrm{~min}$ and were audio-recorded with permission.

\section{Qualitative data analysis}

Interviews and FGDs were simultaneously transcribed and translated from Arabic to English by the lead author, who then open-coded a subset of five transcripts to construct a preliminary codebook. The final author reviewed these codes and transcripts. The entire dataset was then coded by the lead author using Dedoose (www.dedoose.com) with spot-checking by the final author. ${ }^{28}$ Coded data were analysed using an inductive thematic approach to identify key emerging themes.

\section{RESULTS}

Household surveys were conducted from 1 to 20 December 2019. Figure 1 schematically outlines the results from the field survey procedures. In total, 405 households were invited to participate, and 378 agreed (7\% refusal rate). The most common reasons given for refusal were lack of interest or other pressing time commitments. Of 378

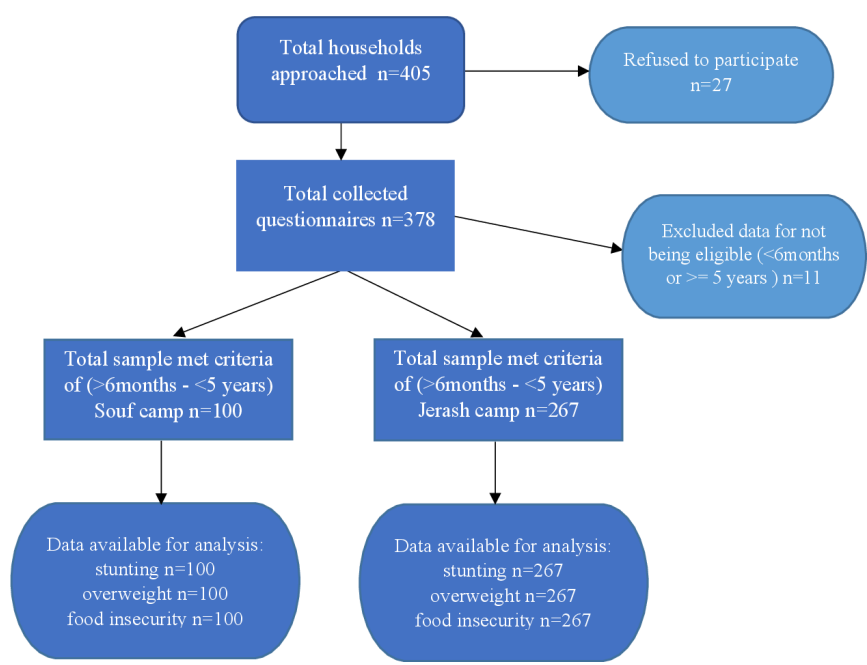

Figure 1 Flow diagram of the study participants.

enrolled houses, 11 were excluded when verifying eligibility (for not having a child of the appropriate age). Therefore, in total, 367 households were included in the analysis (91\% of all households approached).

\section{Quantitative results}

Summary of household and child characteristics

Basic characteristics of participants are given in tables 1-2. In nearly all cases, the survey respondent/ primary caregiver was the biological mother of the child. Households were larger, and attained educational levels were lower in Jerash (table 1). Income instability, unemployment and food insecurity were also more common in Jerash. Differences in total food insecurity were particularly marked, with $45.7 \%$ of households in Jerash classified as highly food insecure versus $26.5 \%$ for Souf (table 1).

The prevalence of stunting was $23.8 \%$ in Jerash camp and $20.4 \%$ in Souf camp ( $\mathrm{p}=0.46)$, and overweight was more common in Jerash camp $(18.2 \%$ vs $7.1 \%$ in Souf camp) ( $\mathrm{p}=0.008$ ) (table 2). In addition, dietary diversity and iron-rich food consumption indicators were significantly lower in Jerash (table 2).

\section{Regression analysis}

We conducted bivariate logistic regression to examine unadjusted associations between characteristics from tables 1-2 and child stunting, overweight and household food insecurity. For stunting, there were no significant associations. For overweight, the crude OR (cOR) was Jerash versus Souf (cOR 2.89 (CI: 1.26 to 6.63), p=0.012) (table 3 ). Jerash residents were more likely to be highly food insecure (cOR 2.33 (CI: 1.4 to 3.87), p<0.001). The number of months with household income in the preceding 6 months also predicted high food insecurity (cOR 1.53 (CI: 1.36 to 1.72 ), $\mathrm{p}<0.0001$ ).

We then used multivariable logistic regression to construct adjusted models. For stunting and overweight, no multivariable model significantly impacted the estimates (results not shown). For food insecurity, we 
Table 1 Descriptive household characteristics of the surveyed Palestine refugee households living in Jerash and Souf camps

\begin{tabular}{|c|c|c|c|}
\hline Characteristic & Jerash $(n=267)$ & Souf $(n=100)$ & $P$ value \\
\hline Primary caregiver woman, \% & 97.8 & 96.1 & 0.32 \\
\hline Primary caregiver age, years (mean \pm SD) & $31.5 \pm 9.6$ & $32.3 \pm 7.6$ & 0.45 \\
\hline Primary caregiver is biological mother, $\%$ & 92.0 & 94.0 & 0.35 \\
\hline Civil status, married, \% & 88.6 & 94.3 & 0.03 \\
\hline Total household size, median (IQR) & $6(3-14)$ & $6(3-11)$ & $<0.001$ \\
\hline Level of education, male head of house & & & $<0.001$ \\
\hline Primary school (1st to 6 th grades) or below, $\%$ & 17.6 & 5.0 & \\
\hline Middle and high school (7th to 13 th grades), $\%$ & 72.3 & 75.0 & \\
\hline Above high school, \% & 10 & 20.0 & \\
\hline Level of education, female head of house & & & $<0.001$ \\
\hline Primary school, \% & 12.3 & 2.0 & \\
\hline Middle and high school, \% & 76.7 & 67.0 & \\
\hline Above high school, \% & 11 & 31.0 & \\
\hline Chronic illness in the family, \% & 76.0 & 24.0 & 0.32 \\
\hline Months received income, last 6 months (median, IQR) & $4(0-6)$ & $6(0-6)$ & $<0.0001$ \\
\hline Head of household employed, \% & 76.0 & 88.0 & 0.01 \\
\hline Head of household employed as day labourer, \% & 42.5 & 36.0 & $<0.03$ \\
\hline Grocery cost per week, Jordanian dinar, median (IQR) & $30(5-150)$ & $20(4-100)$ & $<0.001$ \\
\hline Raw food security scores, median (IQR) ${ }^{\star}$ & $12(8-24)$ & $9(7-24)$ & $<0.01$ \\
\hline High intensity of food insecurity $†$ & $45.7 \%$ & $26.5 \%$ & 0.001 \\
\hline
\end{tabular}

*Raw food insecurity score $>8$.

†Answering 3: 'most of the time'.

constructed a model using the three variables (camp, chronic illness and household income) significant in the bivariate analysis. Only the association with household income (adjusted OR (aOR) 1.50 (CI: 1.33 to 1.69), $\mathrm{p}<0.001)$ remained significant, while residence in Jerash (aOR 0.75 (CI: 0.43 to 1.32)) and chronic illness in the household (aOR 0.64 (CI: 0.40 to 1.05$)$ ) were no longer significant.

\section{Qualitative results}

We conducted explanatory qualitative interviews to better understand differences in food security, child obesity and child dietary indicators between Jerash and Souf. In total, 24 mothers were approached to participate in the in-depth interviews, and 20 agreed (12 in Jerash and eight in Souf). One FGD with stakeholders in each

Table 2 Descriptive child characteristics of surveyed Palestine refugee children living in Jerash and Souf camps

\begin{tabular}{|c|c|c|c|}
\hline Characteristic & Jerash $(n=267)$ & Souf $(n=100)$ & P value \\
\hline Female child, \% & 53.0 & 43.0 & 0.08 \\
\hline Child age, years $($ mean $\pm S D)$ & $2.64 \pm 1.16$ & $2.96 \pm 1.05^{\star}$ & 0.006 \\
\hline Length/height-for-age z-score (HAZ) (mean $\pm S D)$ & $-0.96 \pm 1.87$ & $-0.75 \pm 1.33$ & 0.34 \\
\hline Weight-for-age $z$-score (mean $\pm S D)$ & $-0.09 \pm 1.15$ & $-0.15 \pm 1.04$ & 0.47 \\
\hline Body mass index-for-age $z$-score $(B A Z)(m e a n \pm S D)$ & $0.76 \pm 1.63$ & $0.45 \pm 1.44$ & 0.06 \\
\hline Stunted (<-2 HAZ), \% & 23.8 & 20.4 & 0.46 \\
\hline Overweight (>2 BAZ), \% & 18.2 & 7.14 & 0.008 \\
\hline Double burden of malnutrition (stunted and overweight), \% & 8.6 & 4.0 & 0.09 \\
\hline Continued breastfeeding until 1 year, \% & 83.0 & 72.5 & 0.003 \\
\hline Exclusive breastfeeding until 6 months, \% & 64.7 & 65.3 & 0.82 \\
\hline Food groups consumed/24 hours (mean $\pm S D$ ) & $4.27 \pm 1.5$ & $4.84 \pm 1.4$ & $<0.001$ \\
\hline Minimum dietary diversity (>4 food groups/24 hours), $\%$ & 72.5 & 82.6 & 0.03 \\
\hline Iron-rich food consumption/24 hours, \% & 38.7 & 68.4 & $<0.0001$ \\
\hline
\end{tabular}


Table 3 Unadjusted associations between key household and child characteristics and child underweight, child stunting and household food insecurity

\begin{tabular}{llll}
\hline Characteristic $†$ & Stunting & Overweight & High food insecurity \\
\hline Jerash camp & $0.82(0.46$ to 1.44$)$ & $2.89(1.26 \text { to } 6.63)^{\star}$ & $2.33(1.4 \text { to } 3.87)^{\star *}$ \\
\hline Female child & $0.84(0.51$ to 1.36$)$ & $1.13(0.64$ to 2.0$)$ & $1.09(0.71$ to 1.65$)$ \\
\hline Level of education, female head of house $\neq$ & $0.84(0.51$ to 1.37$)$ & $0.87(0.49$ to 1.56$)$ & $1.31(0.85$ to 2.01$)$ \\
\hline Primary caregiver age & $1.00(0.97$ to 1.02$)$ & $0.99(0.95$ to 1.02$)$ & $1.0(0.98$ to 1.02$)$ \\
\hline Child age & $0.90(0.73$ to 1.12$)$ & $0.78(0.60$ to 1.00$)$ & $1.04(0.87$ to 1.25$)$ \\
\hline Total household size & $1.02(0.91$ to 1.13$)$ & $0.94(0.83$ to 1.07$)$ & $1.08(0.98$ to 1.18$)$ \\
\hline Chronic illness in the family & $1.09(0.78$ to 1.54$)$ & $0.78(0.49$ to 1.21$)$ & $1.65(1.06$ to 2.56$)$ \\
\hline Months received income in last 6 months & $1.05(0.93$ to 1.18$)$ & $1.01(0.87$ to 1.15$)$ & $1.53(1.36 \text { to } 1.72)^{\star \star *}$ \\
\hline Minimum dietary diversity $(>4$ food groups/24 hours) & $1.16(0.65$ to 2.07$)$ & $1.24(0.63$ to 2.48$)$ & -
\end{tabular}

${ }^{*} \mathrm{P}<0.05 ;{ }^{* \star} \mathrm{p}<0.001 ;{ }^{* * *} \mathrm{p}<0.0001$.

†All characteristics are presented as crude OR $(95 \% \mathrm{Cl})$.

†Higher than primary education.

camp (eight participants in Jerash and 10 in Souf) was conducted. Three major themes emerged, which are described in more detail below.

\section{Dynamics of food and food aid}

Formal channels of food aid

Caregivers and FGD participants frequently mentioned different operators working in the camps to address food insecurity. Residents of both camps relied on food and cash assistance from local non-governmental organisations, the Department of Palestinian Affairs and UNRWA. In addition, participants from Souf mentioned additional welfare payments from the Jordanian Department of Social Development, as Jordanian citizens, which participants in Jerash were not eligible to receive. Given the unreliable sources of employment and income in both camps, these formal aid channels were an important source of stability:

I can say $50 \%$ of the refugees live on formal support, with no steady income.-FGD participant, man, Souf resident.

While both mothers and FGD participants valued these support channels, they highlighted several problems. They criticised strict eligibility criteria (aid is often available only for the poorest families), long waiting lists and favouritism among aid organisations and the inadequacy of food rations to meet basic nutritional needs:

The amount of food ration given, even by UNRWA (evouchers), does not cover the families' basics needs. This ration is not even comparable to the monthly welfare support .... So, the food ration is not sustainable for the food supply, and it does not cover their needs.-FGD participant, woman, Souf resident.

\section{Informal channels of food aid}

A majority of caregivers in both camps emphasised the importance of their social circles. Neighbours, family and friends supported families by sharing food or providing money to buy food:
Let me tell you something: people stick together. The other day, one of my friends asked me for money, a tiny amount of money. I didn't have any. I had to ask my family for the amount and gave it to her.-Mother in Souf camp, interview 2.

Participants also highlighted the limitations of this approach, since members of one's close circle were also camp residents and faced the same conditions of resource scarcity.

Other strategies described by mothers to obtain food were by occasionally borrowing money or asking local grocers or food sellers to give them food on credit. In Jerash, mothers also described selling off their possessions, such as clothes, necklaces, furniture and even essential household items, to obtain food for their families:

(Last winter) I said to myself, why sell them (my heater and blankets)? I'll need them. I can't afford to buy a heater or a blanket; let me keep them. This year, I sold them-last week the blanket and this week the heater. So, next week, I have nothing left to sell.-Mother in Jerash camp, interview 6.

\section{Barriers to adequate nutrition for children Unemployment and poverty}

Participants in both camps explored the ways that inadequate income or lack of job security for the head of household impacted children's nutritional status. Importantly, for participants, lack of citizenship status was a primary driver of underemployment. Most had limited access to higher-paying or stable jobs and primarily had to work as unskilled day labourers. Frequently, caregivers used to the Arabic word 'mahromeen' (which roughly translates as destitute in English) to describe this situation:

Int: 'What do you mean by the camp is unfair?'

Mother: 'Yes, in all aspects, it confined us in a place .... It is not a life; I do not know if I am happy or miserable or what exactly. We are "mahromeen." If we were in another area, 
we would have work and not be poor .... I want to work, and my husband wants work; we do not need anyone's aid'. Mother in Jerash camp, interview 6.

Finally, participants described how poor living conditions in the camps, such as crowding, low-quality housing, lack of ventilation and lack of outdoor child-friendly spaces, all harmed child health:

The infrastructure and bad housing conditions affect child health, such as high humidity and bad ventilation inside the house and even between the houses. There is no bright sun or proper air circulation ...; the house's condition affects the children's health. Ceilings are made from Zinco (type of metal for house ceiling), and they leak water during winter.-FGD participant, man, Jerash resident.

\section{Food scarcity and low food quality}

Caregivers discussed the habits and food preferences of their children at length. Many stressed that when they noticed their child not eating well, it was often because the family could not afford to purchase their child's preferred food items. Facing shortages, caregivers resorted to giving their children any form of food they could obtain. For some, this meant that nutrient-poor meals-such as bread and tea-became the norm. Even young infants were affected, as some mothers reported lactational failure due to their own undernutrition. Unable to afford to buy formula milk, they resorted to other alternatives such as giving their infants herbal tea:

Their food should be better ...; my boy is ten months old, and I do not have milk at all, so I make him herbal tea sometimes. Like yesterday, I gave him tea. Anything to get him to be quiet and go to sleep.-Mother in Jerash camp, interview 3 .

In addition, in both camps, mothers stressed their children's low food diversity due to lack of money, the high cost of food and a lack of diversity in food aid rations. Mothers worried that the low food diversity in their child's diet—notably a lack of fruits, vegetables and meats-would harm their child's health:

He lacks diversity in his daily diet, as it lacks fruits and veggies because the family cannot afford fruits and vegetables.-Mother in Jerash camp, interview 5.

Similarly, some caregivers felt that their children were anaemic due to a lack of iron-rich foods in the diet. In Jerash in particular, mothers felt that they could not afford to buy necessary iron-rich foods for their children:

The doctor at the clinic (UNRWA's health centre) prescribed the iron drops from him (her child), as his blood test was eight (haemoglobin level), and told me that I should give my son lentils and beans and squeeze some lemon on it. However, I went back home, and I cooked rice with tomato. This is all that I have.-Mother in Jerash camp, interview 11.

\section{Mothers as managers}

Adjusting expectations to match food availability

Mothers in both camps described how they prioritised feeding their children. In some cases, parents skipped meals or prioritised purchasing the purchase of food items that their children preferred:

Yes, I divide the food quantity equally for each child. Sometimes, I do not eat to spare the food for them. If I bring home fruit, I do not eat it. The same thing goes for my husband.-Mother in Jerash camp, interview 2.

\section{Mothers 'making do'}

In both camps, caregivers highlighted resourcefulness when faced with the day-to-day dilemmas of financial and food insecurity. For example, when faced with a significant shortage of money or food, mothers developed creative recipes from whatever minimal household food supplies remained. They found creative uses for leftovers or added low-cost starchy fillers to stretch food resources:

If I make a dish and feel it will not be enough, I might add fried cauliflower or something like that, which fills the stomach and with nutritional benefits as well.--Mother in Souf camp, interview 3

Another creative strategy used was bartering through small ad hoc exchange economies. For example, mothers in both camps mentioned exchanging or selling items from their food aid rations with neighbours, and some reported stocking up on essential food items to use in the future when they fear that food or money will not be available:

In the days where he works very well, (...) I stock it for the bad days. So then, I can get something from the freezer and cook it. This is our situation, and I must adapt to it.Mother in Souf camp, interview 12.

However, with caregivers' persistent, extreme positions of financial hardship, they reported that their resourcefulness and creativity eventually became stretched too thin:

Mother: 'I have exhausted all my resources; every penny I get is just for basic food, not good food'.

Int: 'What do you mean, "not good food"?'

Mother: 'Yesterday, I had 2 JD (US\$ 3.5). I got bread and zaatar for my children to eat for the day'.

Int: 'What about tomorrow and the day after?'

Mother: 'I do not know. I live day-by-day.'-Mother in Jerash camp, interview 11.

\section{DISCUSSION}

We found a moderate-to-high prevalence of stunting and overweight levels among a representative sample of Palestine refugee children living in the Jerash and Souf refugee camps in Jordan. The overall combined prevalence of stunting and obesity in the two camps was $22 \%$ and $15 \%$, respectively. Since these numbers are just from two camps, 
they are not representative of the overall population of Palestine refugee children in Jordan. Nevertheless, they are roughly three times higher than those reported from the most recent representative 2012 DHS data for Jordanian non-refugee children and starkly worse than the $9.6 \%$ and $0.9 \%$ rates, respectively, reported for the small 2012 refugee subsample. ${ }^{10}$ As another point of comparison, administrative health records data from UNRWA Jordan from 2018 reported a similar rate of stunting for Jerash as we find here but reported only $7 \%$ stunting for Souf. In contrast, we find a prevalence of stunting of around $20 \%$ in Souf. ${ }^{29}$ These differences between both DHS and UNRWA data highlight the need for ongoing, regular community-based data collection on the general population of children living in camps.

Our qualitative results provided insights into the dynamics of child nutrition and food insecurity. While many refugee programmes focus on educating mothers about nutrition, ${ }^{30}$ our study found that caregivers' understanding of nutritional knowledge was high but that cost of diverse foods combined with income restrictions limited their ability to provide their children with highquality diets. In Jerash, interviewees furthermore emphasised the impact of lack of Jordanian citizenship and access to the attendant complementary social services. Similar findings have been documented among Palestine refugees living in Lebanon, who also struggle with the implications of civic and employment restrictions. ${ }^{31}$ In addition, mothers reported choosing cheaper and poorer quality foods as an adaptive cost-saving strategy. Low consumption of meat, fruits and vegetables has similarly been observed among Palestine refugee children in Lebanon $^{32}$ and in other low-middle-income countries. ${ }^{33}$

Stunted children are at increased risk for obesity in low-resource settings around the world. ${ }^{34}{ }^{35}$ Overweight and obesity among children are also strongly associated with economic and civil rights status and high food insecurity. ${ }^{36-38}$ Our findings on childhood obesity were therefore notable, especially in the Jerash camp, with significant increases in prevalence of obesity from the 2012 Jordanian DHS and a substantial double burden of malnutrition. In addition, Palestine refugee camps in Jordan are dramatically overcrowded with limited urban infrastructure and no playgrounds or child-friendly space, as noted by participants in our stakeholder focus groups. These factors limited opportunities for physical activity, which exacerbate the impact of low-quality nutrient-dense foods prevalent in children's diets. ${ }^{37-39}$

Qualitative findings also emphasised that food and/or cash assistance provided by aid organisations was a critical source of support and stability, especially for those without Jordanian citizenship. ${ }^{40}$ Maintenance of these existing aid programmes is critical, but lessons for more sustainable approaches should also be explored but looking at initiatives in different settings. For example, in Lebanon, microfinance programmes and women's community support programmes (eg, 'Healthy Kitchens and Healthy Children') have successfully improved cash flow for refugee women, with benefits for families' food security and income. ${ }^{4142}$

Finally, the qualitative findings highlight the creativity and resilience that caregivers employ when faced with an impossible situation. The social scientist Michel de Certeau reminds us that these everyday tactics of 'making do' are an important form of social resistance, employed by ordinary persons who seek to reclaim their autonomy in the face of political and cultural marginalisation. ${ }^{43}$ Palestine refugees' caregivers in Jordan don't give up: they adapt, they survive and they resist. ${ }^{445}$

\section{Strengths and limitations}

Our study represents an up-to-date community representative study of the nutritional status of Palestine refugee children living in two camps in Jordan. The use of a mixedmethods approach amplifies the voices of caregivers at the centre of this struggle to guarantee the health and future of their families and their children. Limitations of the study include that the perspectives of male heads of households were not collected, which might especially impact the reporting of employment and income data. In addition, the study was only conducted in two specific camps in Jordan, and the findings cannot be generalised to other camps in Jordan or to Palestine refugees living in other host countries.

\section{CONCLUSION}

Our study documents a previously under-reported moderate-to-high prevalence of stunting and overweight levels among Palestine refugee children living in Jerash and Souf refugee camps in Jordan, with a high percentage of food insecurity. Child overweight was higher in Jerash camp compared with Souf camp, driven by food insecurity leading to the consumption of low-quality foods and lack of camp infrastructure.

We believe there is a silent nutritional crisis among Palestine refugee children living in camps in Jordan. This crisis is the result of their long-term status as refugees, with lack of access to meaningful livelihood and essential civil and economic rights for three to four generations. It is essential that international collective efforts led by diverse political, organisational, governmental and international parties work to expand the economic livelihoods of Palestine refugees within their host countries. In addition, efforts to allow refugees to return to their original homes and property must be supported, as outlined in the United Nations General Assembly Resolution 194 (III) and Resolution 32. ${ }^{46}$

Our study provides important data that can help to guide UNRWA in designing future child health interventions among Palestine refugees. We recommend further studies across UNRWA's refugee camps in other host countries, including Syria, Lebanon, the Gaza Strip and the West Bank, and we suggest more detailed investigations of other nutritional determinants, such as anaemia, among children under 5 living in Palestine refugee camps in Jordan. 
Acknowledgements UNRWA Health Department in Jordan Field Office and Headquarters, data collectors from the women programme centres and all Palestine refugee mothers who agreed to be part of the study.

Contributors NK, HG, JM and PJR did the conception and design of the study; NK and PJR did the collection and assembly of data; NK, HG and PJR did the data analysis and interpretation; and all authors had participated in manuscript writing and final approval of the transcript.

Funding Fund was granted by Global Health and Social Medicine Department at Harvard Medical School, 2019.

Competing interests None declared.

Patient consent for publication Not required.

Ethics approval Institutional Review Board (IRB) approval was obtained from the Harvard Medical School IRB (HMS-IRB19-0581) and the UNRWA Research Review Board. The project was supported by the director of health department at UNRWA Headquarters as well as the chiefs of health programmes and relief and social services at the UNRWA Jordan Field Office.

Provenance and peer review Not commissioned; externally peer reviewed.

Data availability statement All data relevant to the study are included in the article or uploaded as supplementary information. The data are deidentified participant data; some restrictions will apply for the availability of data.

Supplemental material This content has been supplied by the author(s). It has not been vetted by BMJ Publishing Group Limited (BMJ) and may not have been peer-reviewed. Any opinions or recommendations discussed are solely those of the author(s) and are not endorsed by BMJ. BMJ disclaims all liability and responsibility arising from any reliance placed on the content. Where the content includes any translated material, BMJ does not warrant the accuracy and reliability of the translations (including but not limited to local regulations, clinical guidelines, terminology, drug names and drug dosages), and is not responsible for any error and/or omissions arising from translation and adaptation or otherwise.

Open access This is an open access article distributed in accordance with the Creative Commons Attribution Non Commercial (CC BY-NC 4.0) license, which permits others to distribute, remix, adapt, build upon this work non-commercially, and license their derivative works on different terms, provided the original work is properly cited, appropriate credit is given, any changes made indicated, and the use is non-commercial. See: http://creativecommons.org/licenses/by-nc/4.0/.

ORCID iD

Nada AbuKishk http://orcid.org/0000-0002-9694-4860

\section{REFERENCES}

1 United Nations High Commissioner for Refugees (UNHCR). What is a refugee. who is a refugee, 2021. Available: https://www. unrefugees.org/refugee-facts/what-is-a-refugee/

2 United Nation Relief Work Agency for Palestine Refugee (UNRWA). Palestine refugees. Available: https://www.unrwa.org/palestinerefugees [Accessed Dec 2020].

3 United Nation relief and Work Agency for Palestine refugee. United nations General assembly resolution 302. A/RES/302 (IV) 1949 https://www.unrwa.org/content/general-assembly-resolution-302

4 Massad S, Deckelbaum RJ, Gebre-Medhin M, et al. Double burden of undernutrition and obesity in Palestinian schoolchildren: a crosssectional study. Food Nutr Bull 2016;37:144-52.

5 Kroening ALH, Dawson-Hahn E. Health considerations for immigrant and refugee children. Adv Pediatr 2019;66:87-110.

6 Baker JR, Raman S, Kohlhoff J, et al. Optimising refugee children's health/wellbeing in preparation for primary and secondary school: a qualitative inquiry. BMC Public Health 2019;19:812.

7 Chaaban J, Ghattas H, Habib R. Socio-Economic survey of Palestinian refugees in Lebanon. American University of Beirut, 2010: 8.

8 United Nation Relief and Work Agency for Palestine refugee (UNRWA). Where we work. Jordan, 2021. Available: https://www. unrwa.org/where-we-work/jordan

9 United Nation Relief and Work Agency for Palestine refugee (UNRWA). Health department annual report 2019.p.45, 2021. Available: https://www.unrwa.org/2019UNRWAHealthAnnualReport

10 Department of Statistics [Jordan] and ICF International. Jordan population and family health survey 2012. published 2013 , P 144147. Available: http://dhsprogram.com/pubs/pdf/FR282/FR282.pdf

11 Department of Statistics and ICF International. Jordan population and family health survey 2017-2018.
12 van den Berg MM, Madi HH, Khader A, et al. Increasing neonatal mortality among Palestine refugees in the Gaza strip. PLoS One 2015;10:e0135092.

13 Abu Kishk N, Hababeh M, Saleh S, et al. Prevalence of anaemia in children newly registered at UNRWA schools: a cross-sectional study. The Lancet 2019;393:S35. Abstract1.

14 ÅA T, Zhang H. Progress, challenges, diversity: insights into the socio-economic conditions of Palestinian refugees in Jordan. Fafo, 2013.

15 Creswell JW, Clark VL. Designing and conducting mixed methods research. Sage publications, 2017.

16 Department of statistic,. Kingdom of Jordan. Available: https://worl dpopulationreview.com/countries/jordan-population

$17 \varnothing$ V. Geographic information retrieval: an overview. Department of computer and information science, Norwegian University of technology and science, 2004. Available: https://qgis.org/en/site/

18 Research Electronic Database Capture (REDCap). Vanderbilt University. National Institutes of health (NIH/NCATS UL1 TR000445, 2004.

19 United Nation Children's Fund (UNICEF). Multiple indicator cluster survey (MICs). manual for anthropometry, 2015. Available: https:// mics.unicef.org/tools [Accessed April, 2020].

20 World Health Organization. Nutrition landscape information system (NLIS) country profile indicators: interpretation guide. WHO, 2010. ISBN: 9789241599955

21 The Lancet. A future direction for tackling malnutrition. Lancet 2020;395:2.

22 Ballard T, Kepple A, Cafiero C. The food insecurity experience scale: development of a global standard for monitoring hunger worldwide. Fao, 2013. Available: http://www.fao.org/in-action/voices-of-thehungry/using-fies/en/ [Accessed August, 2019].

23 Coates J, Swindale A, Bilinsky P. Household food insecurity access scale (HFIAS) for measurement of household food access: indicator guide. USAID, 2007

24 World Health Organization. Indicators for assessing infant and young child feeding practices: conclusions of a consensus meeting held 6-8 November 2007. Washington DC, USA: WHO, 2008. ISBN: 978 9241596664 .

25 StataCorp. Stata Statistical Software: Release 16. College Station, TX: StataCorp LLC, 2019.

26 WHO. AnthroPlus for personal computers Manual: Software for assessing growth of the world's children and adolescents. Geneva: WHO, 2009. http://www.who.int/growthref/tools/en/

27 Patton MQ. Qualitative research \& evaluation methods: Integrating theory and practice. Sage publications, 2014.

28 SocioCultural Research Consultants, LLC. Dedoose Version 7.5.16 [computer program. Los Angeles, CA, 2017.

29 United Nation Relief and Work Agency for Palestine Refugee (UNRWA). Health department annual report 20182021 https://www. unrwa.org/resources/reports/health-department-annual-report-2018

30 Güngör A, Çuhacı Çakır B, Ateș S, et al. Syrian refugee mothers' knowledge levels of childhood wellness: a program evaluation. Avicenna J Med 2020;10:106-10.

31 Ghattas H, Sassine AJ, Seyfert K, et al. Prevalence and correlates of food insecurity among Palestinian refugees in Lebanon: data from a household survey. PLoS One 2015;10:e0130724.

32 Jamaluddine Z, Sahyoun NR, Choufani J, et al. Child-Reported food insecurity is negatively associated with household food security, socioeconomic status, diet diversity, and school performance among children attending un relief and works agency for Palestine refugees schools in Lebanon. $J$ Nutr 2019;149:2228-35.

33 Webb MF, Chary AN, De Vries TT, et al. Exploring mechanisms of food insecurity in Indigenous agricultural communities in Guatemala: a mixed methods study. BMC Nutr 2016;2.

34 Hoffman DJ, Sawaya AL, Verreschi I, et al. Why are nutritionally stunted children at increased risk of obesity? studies of metabolic rate and fat oxidation in shantytown children from São Paulo, Brazil. Am J Clin Nutr 2000;72;): :702-7. Vol.

35 Mahmudiono T, Nindya T, Andrias D, et al. Household food insecurity as a predictor of stunted children and overweight/obese mothers (SCOWT) in urban Indonesia. Nutrients 2018;10:535

36 Conrad D, Capewell S. Associations between deprivation and rates of childhood overweight and obesity in England, 2007-2010: an ecological study. BMJ Open 2012;2:e000463.

37 Zhu Y, Mangini LD, Hayward MD, et al. Food insecurity and the extremes of childhood weight: defining windows of vulnerability. Int $J$ Epidemiol 2020;49:519-27.

38 Eisenmann JC, Gundersen C, Lohman BJ, et al. Is food insecurity related to overweight and obesity in children and adolescents? A summary of studies, 1995-2009. Obes Rev 2011;12:e73-83. 
39 Farrell P, Thow AM, Abimbola S, et al. How food insecurity could lead to obesity in LMICs: when not enough is too much: a realist review of how food insecurity could lead to obesity in low- and middle-income countries. Health Promot Int 2018;33:812-26.

40 Khawaja M, Tiltnes AA. On the margins: migration and living conditions of palestinian CAMP refugees in Jordan. Fafo, Institute for Applied Social Science, 2002.

41 Ghattas H, Choufani J, Jamaluddine Z, et al. Linking women-led community kitchens to school food programmes: lessons learned from the healthy Kitchens, healthy children intervention in Palestinian refugees in Lebanon. Public Health Nutr 2020;23:914-23.

42 United Nation relief and Work Agency for Palestine refugee.

Microfinance program. UNRWA microfinance loan brings blessings to female entrepreneur, 2020. Available: https://wwwunrwaorg/ newsroom/videos/unrwa-microfinance-loan-brings-blessingsfemale-entrepreneur

43 Certeau MJ. The practice of everyday life, 1988: 1-111.

44 Higashi RT, Craddock Lee SJ, Pezzia C, et al. Family and social context contributes to the interplay of economic insecurity, food insecurity, and health. Ann Anthropol Pract 2017;41:67-77.

45 Alinovi L, Mane E, Romano D. Towards the measurement of household resilience to food insecurity: applying a model to Palestinian household data. deriving food security information from national household budget surveys. Rome, Italy: Food and Agriculture Organization of the United Nations, 2008: 137-52.

46 Nation Relief Work Agency for Palestine Refugee (UNRWA). Resolution 194, 2021. Available: https://wwwunrwaorg/content/ resolution-194 